\title{
Endosaccular Treatment of Very Large and Giant Intracra- nial Aneurysms with Parent Artery Preservation : Single Center Experience with Long Term Follow-up
}

\author{
Chae Wook Huh, M.D., Jae Il Lee, M.D., ${ }^{2}$ Chang Hwa Choi, M.D., ${ }^{2}$ Tae Hong Lee, M.D., ${ }^{3}$ Jae Young Choi, M.D., ${ }^{4}$ Jun Kyeung Ko, M.D. ${ }^{2}$ \\ Department of Neurosurgery, Inje University Haeundae Paik Hospital, Busan, Korea \\ Departments of Neurosurgery, ${ }^{2}$ Diagnostic Radiology, ${ }^{3}$ Medical Research Institute, Pusan National University Hospital, Pusan National Univer- \\ sity School of Medicine, Busan, Korea. \\ Department of Neurosurgery, ${ }^{4}$ Kosin University Gaspel Hospital, Busan, Korea.
}

Objective : Very large $(20-25 \mathrm{~mm})$ and giant $(\geq 25 \mathrm{~mm}$ ) intracranial aneurysms have an extremely poor natural course, and treatment of these aneurysms remains a challenge for endovascular and surgical strategies. This study was undertaken to describe our experiences of endosaccular treatment of very large and giant intracranial aneurysms with parent artery preservation.

Methods : From January 2005 to October 2016, twenty-four very large or giant aneurysms in 24 patients were treated by endosaccular coil embolization with parent artery preservation. Nine (37.5\%) aneurysms were ruptured and 15 were unruptured, and of these 15, 11 were symptomatic cases and 4 were incidentally discovered. The cohort comprised 17 women and 7 men of mean age 58.5 years (range, 26-82). Mean aneurysm size was $26.0 \mathrm{~mm}$ (range, 20-39) and 13 of the 24 aneurysms were giant.

Results : Immediate angiographic results were complete occlusion in nine (37.5\%) cases, remnant neck in six (25.0\%), and remnant sac in nine (37.5\%). Overall procedural related morbidity and mortality rates were $12.5 \%$ and $4.2 \%$, respectively. Angiographic follow-up was available in 16 patients (66.7\%). Mean and median follow-up periods were 27.2 (range, 2-77) and 10.5 months, respectively. In 12 cases $(12 / 16,75 \%)$ stable occlusion was achieved, four cases $(4 / 16,25 \%)$ had recanalized, and two of these were retreated with additional coiling. At clinical follow-up of the nine ruptured cases, three patients (33.3\%) achieved a good clinical outcome (Glasgow outcome scale [GOS] score of 4 or 5), two (22.2\%) a poor outcome (GOS score of 2 or 3 ), and four patients (44.4\%) expired (GOS 1). On the other hand, of the 15 unruptured cases, 13 patients (86.7\%) achieved a good clinical outcome (GOS 4 or 5), one patient a poor outcome (GOS score of 2 or 3), and one patient expired (GOS 1).

Conclusion : The present study shows endosaccular treatment of very large or giant intracranial aneurysms with parent artery preservation is both feasible and effective with acceptable morbidity and mortality.

Key Words : Giant intracranial aneurysm · Embolization · Reconstruction.

- Received : June 12, 2017 •Revised : August 14, 2017 •Accepted : August 31, 2017

- Address for reprints : Jae II Lee, M.D.

Department of Neurosurgery, Medical Research Institute, Pusan National University Hospital, 179 Gudeok-ro, Seo-gu, Busan 49241, Korea

Tel : +82-51-240-7257, Fax : +82-51-247-7165, E-mail : medifirst@pusan.ac.kr

This is an Open Access article distributed under the terms of the Creative Commons Attribution Non-Commercial License (http://creativecommons.org/licenses/by-nc/4.0) which permits unrestricted non-commercial use, distribution, and reproduction in any medium, provided the original work is properly cited. 


\section{INTRODUCTION}

Treatment of very large $(20-25 \mathrm{~mm})$ and giant $(\geq 25 \mathrm{~mm})$ intracranial aneurysms remains a challenge for interventionists and surgeons because of their sizes, intraluminal thrombosis, calcification, and incorporated perforating arteries ${ }^{6}$. However, recent advancements in endovascular techniques and devices have increased the scope of endovascular approaches to these lesions. Currently, a few series have reported on the endovascular treatment of large and giant intracranial aneurysms with parent artery preservation. Large intracranial aneurysm is usually defined as an aneurysm with a maximum diameter ranging from 10 to $25 \mathrm{~mm}$, but this size range may be inappropriate for the definition of a single disease entity. Therefore, we defined a very large aneurysm as one with a maximum diameter of $\geq 20 \mathrm{~mm}$ but $<25 \mathrm{~mm}$, and a giant aneurysm as one with a maximum diameter of $\geq 25 \mathrm{~mm}$.

The aim of this study was to report the long-term outcomes of very large and giant aneurysms treated endovascularly with parent artery preservation and to document the incidences of complications, recurrences, and retreatment.

\section{MATERIALS AND METHODS}

\section{Patient population}

The medical records of patients that underwent endosaccular treatment for a very large or a giant intracranial aneurysm were retrospectively reviewed. Between January 2005 and October 2016, 24 (2.2\%) among 1094 embolized aneurysms were very large or giant intracranial aneurysms treated by endovascular coiling with parent artery preservation. All aneurysms were of the saccular type as confirmed by computed tomography (CT) or magnetic resonance imaging (MRI) and digital subtraction angiography (DSA). Two neurovascular surgeons and two neurointerventionists carefully reviewed angiograms to decrease inter-observer variability. Patient demographics, aneurysm characteristics, treatment techniques, and angiographic and clinical outcomes were reviewed with focus on angiographic results, recurrence rates, and clinical outcomes.

\section{Endovascular technique}

Two vascular neurosurgeons and two interventional neuroradiologists evaluated the 24 cases for endovascular treatment.
Informed consent for all procedures was obtained from patients or next of kin. Most of the aneurysms were coiled under light sedation with dexmedetomidine (maintenance dose; 0.6$1.0 \mathrm{mcg} / \mathrm{kg} / \mathrm{hr}$ ) or propofol sedation. In the majority of cases, the right femoral artery was accessed using a 6-French (Fr) 80 $\mathrm{cm}$ long Shuttle sheath (Cook, Bloomington, IN, USA). In one case, direct common carotid artery puncture was performed because of the tortuous natures of the aorta and proximal carotid artery. A 6-Fr guiding catheter (Envoy, Cordis, Miami Lakes, FL, USA) was then placed in the distal internal carotid artery (ICA) as far as possible. After attaining access to the femoral artery, a bolus of 3000 IU heparin was administered intravenously at the beginning of the procedure in non-hemorrhagic cases. However, in cases of aneurysm rupture, heparin was administered after microcatheter selection of the aneurismal sac. Regardless of rupture, an additional 1000 IU bolus of heparin was administered hourly to maintain an activated clotting time of $\geq 250$ seconds. All sheaths, guiding catheters, and microcatheters were continually flushed with heparinized saline (at a concentration of $1000 \mathrm{IU}$ of heparin per $1000 \mathrm{~mL}$ of saline). In non-hemorrhagic cases, dual antiplatelet premedication, consisting of $75 \mathrm{mg}$ clopidogrel and $100 \mathrm{mg}$ aspirin, was administered for 7 days before the endovascular procedure. Postoperatively, dual antiplatelet therapy (clopidogrel and aspirin) was maintained for at least 6 months in all cases.

Endovascular treatment was performed using a simple coil $(n=5,20.8 \%)$, a stent assisted coil $(n=15,62.5 \%)$, or a balloon assisted coil $(n=4,16.7 \%)$. Simple coiling was performed in most using the two-catheter technique with tailored microcatheter steam shaping. When the two-catheter technique could not be applied or failed, adjunctive techniques (balloonassisted or stent-assisted coiling) were used to achieve satisfactory results. Theoretically, the two-catheters technique improves packing density and ensures the coil mass do not protrude into the parent artery. Coils were inserted within aneurysms as densely as possible, or until another coil could not be inserted, without compromising the parent artery.

After all procedures, multiple angiographic projections were obtained to assess results, and if no complication was evident by final angiography performed at 30 minutes after coiling, procedures were completed. In addition, non-enhanced brain CT was performed immediately after procedures to confirm the absence of possible complications. 


\section{Clinical and angiographic follow-up assessments}

All patients with subarachnoid hemorrhage (SAH) were initially evaluated according to the Hunt-Hess $(\mathrm{H}-\mathrm{H})$ grading system. Patients without a history of SAH were considered $\mathrm{H}-\mathrm{H}$ grade 0 . Grades $0-3$ were considered to indicate good clinical preoperative status and grades $4-5$ to indicate poor status. Post-procedural and follow-up clinical outcomes were assessed using the Glasgow outcome scale (GOS), where; $1=$ death, $2=$ persistent vegetative state, $3=$ severe disability, $4=$ moderate disability, and $5=$ low disability. Procedure related permanent morbidity was defined as a change in GOS score associated with intervention. Initial angiographic results were classified using the Raymond classification as; complete occlusion (CO), remnant neck (RN), or remnant sac $(\mathrm{RS})^{17)}$. Recurrence of coiled aneurysms was classified as; stable occlusion (SO; defined as no interval change or further obliteration as compared with initial post embolization angiograms), minor recanalization (MIR, recanalized volume of $<20 \%$ ), major recanalization (MAR, recanalized volume of $\geq 20 \%$ of initial aneurismal volume), or regrowth (defined as aneurismal dilatation or de novo appearance of a daughter sac). Major recanalization or regrowth cases were considered candidates for retreatment on an individual basis.

\section{RESULTS}

\section{Baseline patient and aneurysm characteristics and treatment modalities}

Angiographic (DSA or MRA) and clinical follow-up records were analyzed. The study cohort consisted of 17 females and seven males of mean age 58.5 years (range, 26-82). Nine $(37.5 \%)$ patients presented with SAH. H-H grades in ruptured cases were as follows; grade 2 in one patient, grade 3 in three patients, grade 4 in three patients, and grade 5 in two patients. Five patients $(20.8 \%)$ had a poor pre-procedural condition ( $\mathrm{H}-\mathrm{H}$ grade 4 or 5 ). Of the 15 unruptured aneurysms, four were incidentally discovered, 10 were associated with cranial nerve palsy attributed to mass effect, and one was diagnosed after a transient ischemic attack (TIA). Mean aneurysm size was $26.0 \mathrm{~mm}$ (range, 20-39) and 13 were giant aneurysms. Twenty aneurysms (83.3\%) were located in the anterior circulation, that is, 14 in the internal carotid artery (ICA), two in the middle cerebral artery (MCA), three in the posterior commu- nicating artery, and one in the persistent primitive trigeminal artery. Four aneurysms (16.7\%) were located in the posterior circulation, that is, three in the basilar artery top and one in the vertebro-basilar junction.

Giant aneurysm cases were tested by balloon test occlusion (BTO) and all failed to show tolerance. All aneurysms were embolized with parent artery preservation. Stents were used in $15(62.5 \%)$ cases. The clinical presentations and characteristics of patients are summarized in Tables 1 and 2 .

\section{Immediate angiographic results and complications}

Immediate post-procedure angiograms revealed; $\mathrm{CO}$ in nine patients (37.5\%), RN in six (25.0\%), and RS in nine patients (37.5\%). Packing densities ranged from $12 \%$ to $20 \%$. Complications were as follows; five $(20.8 \%)$ acute thromboembolism, one (4.2\%) parent artery dissection, one $(4.2 \%)$ puncture site hematoma, and three (12.5\%) delayed cerebral infarction. All cases of acute thromboembolism were resolved by chemical or mechanical thrombolysis, but one patient encountered delayed cerebral infarction in right MCA territory. Delayed parent artery occlusion due to arterial dissection was encountered in one case of ophthalmic segment ICA giant aneurysm, and several days after coil embolization, the patient experienced a TIA. Angiography confirmed complete occlusion of ICA with sufficient collateral flow through the anterior communicating artery. Induced hypertension therapy was initiated and the patient recovered fully without ischemic symptoms. Accordingly, the procedure related permanent morbidity rate was $12.5 \%$ (3/24). Fig. 1 demonstrated coiling of symptomatic unruptured left ICA giant aneurysms with parent artery preservation.

\section{Follow-up angiographic and clinical outcomes}

Follow-up angiograms were available for 16 patients (66.7\%); the other eight were excluded due to death (five patients) of follow-up loss (three patients). Mean angiographic follow-up period was 27.2 months (range, 2- 77; median, 10.5 months). Of these 16 patients, 11 cases achieved SO, four cases were recanalized (2 MAR, 2 MIR), and one presented with delayed parent artery occlusion as mentioned above. The two patients that presented with MAR were retreated by additional coil embolization. Retreatment results were confirmed as SO by follow-up angiography. At the time of writing, the two patients with MIR were scheduled for follow-up angiography. 
Endosaccular Treatment of Large and Giant Intracranial Aneurysms | Huh CW, et al.

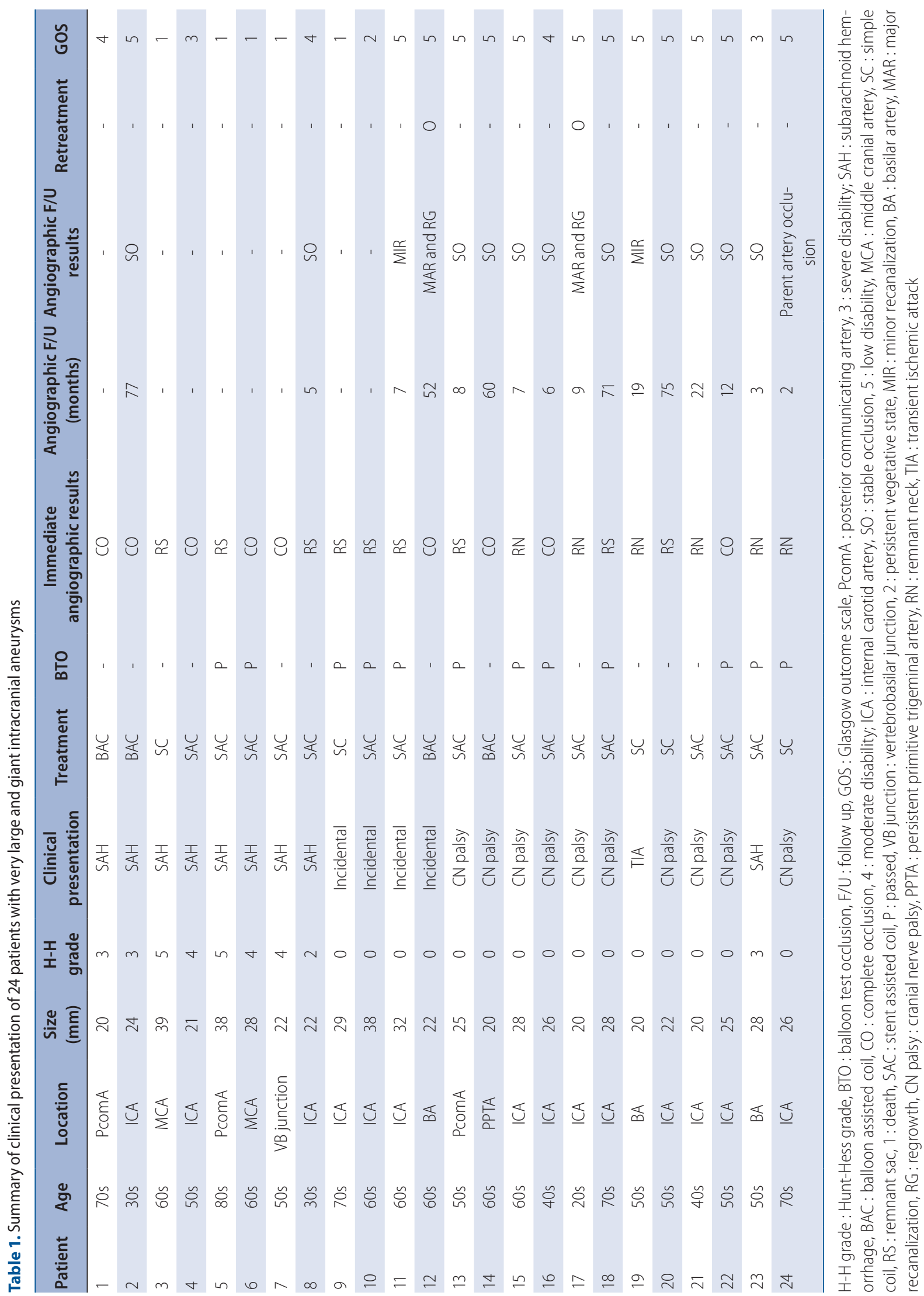


Table 2. Characteristics of patients

\begin{tabular}{|c|c|}
\hline No. of aneurysms (patients) & 24 cases ( 24 patients) \\
\hline Mean age & $58.5(26-82)$ \\
\hline Female/male & $17(70.8) / 7(29.2)$ \\
\hline \multicolumn{2}{|l|}{ Initial aneurysm state } \\
\hline Rupture & 9/24 (37.5) \\
\hline Unruptre & $15 / 24(62.5)$ \\
\hline \multicolumn{2}{|l|}{ Aneurysm size } \\
\hline Large (20-24 mm) & $11 / 24(45.8)$ \\
\hline Giant ( $\geq 25 \mathrm{~mm}$ ) & $13 / 24(54.2)$ \\
\hline \multicolumn{2}{|l|}{$\mathrm{H}$-H grade } \\
\hline 0 (unruptred) & 15 \\
\hline 1 & 0 \\
\hline 2 & 1 \\
\hline 3 & 3 \\
\hline 4 & 3 \\
\hline 5 & 2 \\
\hline \multicolumn{2}{|l|}{ Unruptured aneurysms } \\
\hline CN palsy & 10 \\
\hline TIA & 1 \\
\hline Incidental & 4 \\
\hline \multicolumn{2}{|l|}{ Aneurysm location } \\
\hline ICA(petro-cavernous) & 14/24 (58.3) \\
\hline MCA bifurcation & 2/24 (8.3) \\
\hline PcomA & $3 / 24(12.5)$ \\
\hline PPTA & $1 / 24(4.2)$ \\
\hline BA & $3 / 24(12.5)$ \\
\hline VB junction & $1 / 24(4.2)$ \\
\hline
\end{tabular}

Values are presented as number (\%). H-H grade : Hunt-Hess grade, CN palsy : cranial nerve palsy, TIA : transient ischemic attack, ICA : internal carotid artery, MCA : middle cranial artery, PcomA : posterior communicating artery, PPTA : persistent primitive trigeminal artery, BA : basilar artery, VB junction : vertebrobasilar junction

At clinical follow-up visits, 16 patients (66.7\%) had a GOS score of 4 or 5 (good outcome), three patients (12.5\%) had a GOS score of 2 or 3 (poor outcome), and five patients had expired (an overall mortality rate of $20.8 \%$ [5/24]). However, among ruptured cases, four patients $(44.4 \%, 4 / 9)$ expired due to an initial poor clinical grade. The mortality rate among unruptured cases was $6.7 \%(1 / 15)$, and this was attributed to delayed MCA territory malignant infarction. Angiographic and clinical outcomes are summarized in Table 3.
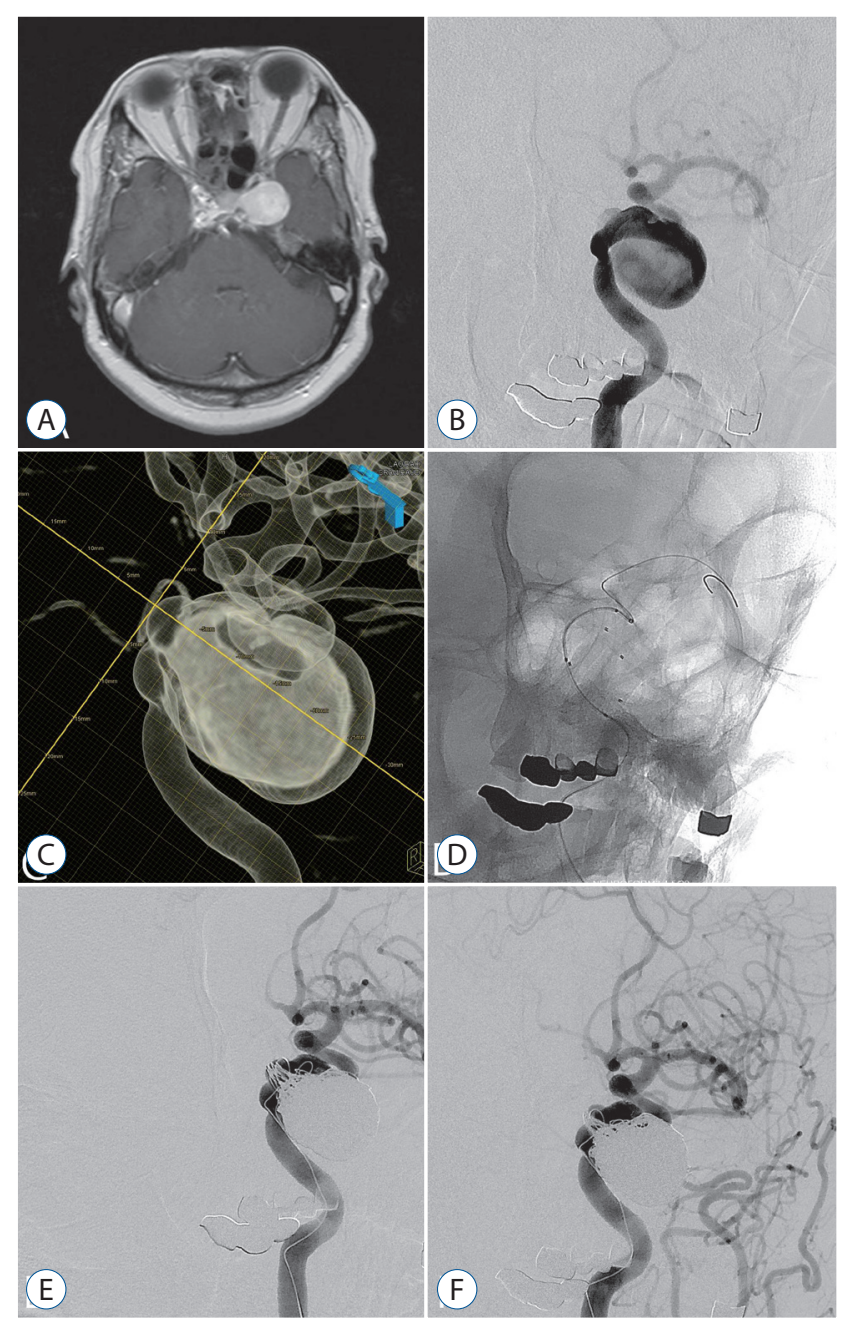

Fig. 1. A 58-year old woman with left 6 th cranial nerve palsy patient. A : A pre-procedural axial T1-weighted magnetic resonance image showing a intracranial aneurysm. B : A left internal carotid artery (ICA) angiography. $C$ : A 3-dementional reconstruction image showing a giant aneurysm arising from left cavernous segment ICA. D : The aneurysm was coiled by the multiple catheters with stent. E : A post-procedural angiography showing small remnant neck of the aneurysm with parent artery preservation. $\mathrm{F}$ : Seven months follow-up angiography showing stable occlusion of the aneurysm.

\section{DISCUSSION}

Very large and giant intracranial aneurysms have an extremely poor natural history due to the possibilities of severe hemorrhage, mass effect, or thromboembolic complications. Peerless and Drake ${ }^{15)}$ reported 2- and 6-year mortality rates of $68 \%$ and $85 \%$, and Kodama et al. ${ }^{12)}$ four cases were recanalized (2 MAR, 2 MIR), and one presented with delayed parent artery occlusion as mentioned above. The two patients that 
presented with MAR were retreated by additional coil embolization. Retreatment results were confirmed as SO by followup angiography. At the time of writing, the two patients with

Table 3. Summary of angiographic and clinical outcomes

\begin{tabular}{lc}
\hline Status & Value \\
\hline Immediate angiographic results & \\
CO & $9 / 24(37.5)$ \\
RN & $6 / 24(25.0)$ \\
RS & $9 / 24(37.5)$ \\
Angiographic follow-up results & \\
Parent artery occlusion & $1 / 16(6.3)$ \\
SO & $11 / 16(68.8)$ \\
MIR & $2 / 16(12.5)$ \\
MAR or RG & $2 / 16(12.5)$ \\
Clinical follow-up results & \\
Ruptured aneurysms & \\
GOS 5 or 4 (good outcome) & $3 / 9(33.3)$ \\
GOS 3 or 2 (poor outcome) & $2 / 9(22.2)$ \\
GOS 1 (death) & $4 / 9(44.4)$ \\
Unruptured aneurysms & $13 / 15(86.7)$ \\
GOS 5 or 4 (good outcome) & $1 / 15(6.7)$ \\
GOS 3 or 2 (poor outcome) & $1 / 15(6.7)$ \\
GOS 1 (death) & \\
\hline
\end{tabular}

Values are presented as number (\%). CO : complete occlusion, RN : remnant neck, RS : remnant sac, SO : stable occlusion, MIR : minor recanalization, MAR : major recanalization, $\mathrm{RG}$ : regrowth, GOS : Glasgow outcome scale
MIR were scheduled for follow-up angiography.

At clinical follow-up visits, 16 patients (66.7\%) had a GOS score of 4 or 5 (good outcome), three patients (12.5\%) had a GOS score of 2 or 3 (poor outcome), and five patients had expired (an overall mortality rate of 20.8\% [5/24]). However, among ruptured cases, four patients (44.4\%, 4/9) expired due to an initial poor clinical grade. introduction, it appears quite inappropriate to consider large aneurysms (generally defined as having a maximum diameter of $\geq 10 \mathrm{~mm}$ ) and very large or giant aneurysms (maximum diameter of $\geq 20 \mathrm{~mm}$ ) as a single disease entity. Accordingly, we limited this study to very large and giant aneurysms.

Traditional therapeutic option for very large and giant aneurysm was direct surgical clipping or trapping with or without bypass surgery. However, surgical treatment is often challenging and can be associated with significant morbidity ${ }^{4,10,18,19)}$. Nowadays, endovascular treatment has largely replaced open surgery for small to medium sized intracranial aneurysms ${ }^{4,17,21)}$. However, the endovascular treatment of very large and giant aneurysm is challenging due to the incompleteness of results. Sluzewski et al. ${ }^{18)}$ reported two major cause for very large and giant aneurysm recanalization, that is, coil compaction due to thrombus resolution in the sac, and insufficient packing density due to an increase in aneurysmal volume. Therefore, in our opinion, complete occlusion is an important goal of initial treatment for very large and giant aneurysms in particular, and strict follow-up angiography should be viewed as mandatory. In the present study, CO was observed after

Table 4. Comparison of outcomes in endovascular series of large and giant intracranial aneurysms

\begin{tabular}{|c|c|c|c|c|c|c|c|c|c|}
\hline Study & $\begin{array}{c}\text { No. of } \\
\text { aneurysm }\end{array}$ & $\begin{array}{l}\text { Enroll } \\
\text { ment }\end{array}$ & $\begin{array}{c}\text { Recanal } \\
\text { ization (1st f/u) } \\
(\%)\end{array}$ & $\begin{array}{c}\text { Procedural } \\
\text { morbidity (\%) }\end{array}$ & $\begin{array}{l}\text { Overall } \\
\text { mortality } \\
(\%)\end{array}$ & $\begin{array}{c}\text { Good } \\
\text { outcome } \\
\text { (GOS 4-5) (\%) }\end{array}$ & $\begin{array}{c}\text { Poor } \\
\text { outcome } \\
\text { (GOS 1-3) (\%) }\end{array}$ & Publish & \\
\hline Gruber et al. $^{7)}$ & 31 & $\geq 20$ & - & 13.3 & 6.7 & 73.3 & 26.7 & 1999 & Without PAO \\
\hline Sluzewski et al. ${ }^{18)}$ & 31 & $\geq 20$ & 69.0 & 12.9 & 17.2 & 79.3 & 20.7 & 2003 & Without PAO \\
\hline Li et al. ${ }^{14)}$ & 20 & $\geq 20$ & 21.1 & 5.0 & 5.0 & 95.0 & 5.0 & 2007 & Include PAO \\
\hline Jahromi et al. ${ }^{10)}$ & 39 & $\geq 25$ & - & 26.0 & 29.0 & 63.0 & 37.0 & 2008 & Include PAO \\
\hline Hauck et al. ${ }^{9)}$ & 15 & $\geq 20$ & 80.0 & 0 & 0 & 93.3 & 6.7 & 2009 & Without PAO \\
\hline Ha and Jang et al. & 9 & $\geq 25$ & 22.2 & 0 & 11.1 & 88.9 & 11.1 & 2012 & Without PAO \\
\hline Present study & 24 & $\geq 20$ & 25.0 & 12.5 & 20.8 & 66.7 & 33.3 & & Without PAO \\
\hline Ruptured & & - & & & $(44.4)$ & & & & \\
\hline Unruptred & & - & & & $(6.7)$ & & & & \\
\hline
\end{tabular}

f/u : follow up, GOS : Glasgow outcome scale, PAO : parent artery occlusion 
initial treatment in $37.5 \%$ of patients $(9 / 24)$ and recurrence in $25 \%$, that is, in 4 of the 16 patients that underwent follow-up DSA. These values are similar to those reported by several studies on the recurrence rates (21.1-80.0\%) of large and giant aneurysms (Table 4$)^{7-9,18)}$.

Recent technique advancements, for example, compliant balloons, intracranial stents, and flow diverters, have facilitated the endovascular treatments of very large and giant aneurysms. In particular, flow diverters, which reduces hemodynamic interactions between aneurysms and parent arteries, have recently emerged as a new endovascular treatment for large and giant aneurysms. Brinjikji et al. ${ }^{3)}$ reported initial complete occlusion rates of $76 \%$ overall, $80 \%$ for small aneurysms $(<10 \mathrm{~mm}), 74 \%$ for large aneurysms $(\geq 10 \mathrm{~mm}$ and $<25 \mathrm{~mm}$ ), and $76 \%$ for giant aneurysms; procedural morbidity and mortality rates were $5 \%$ and $4 \%$, respectively. Becske et al. ${ }^{1,2)}$ reported treatment of uncoilable or failed aneurysms (mean size $18.2 \mathrm{~mm}$ ) with flow diverters achieved complete occlusion rates of $90 \%$ and $93.4 \%$ at 1 - and 3-year follow-up visits, respectively. el-Chalouhi et al. ${ }^{5)}$ concluded flow diverters were more cost effective than conventional coiling in aneurysmal volume of $\geq 0.9 \mathrm{~mL}$. However, flow diverters should be considered more prudently as a therapeutic option. The major limitations of flow diverters are as follows; the need for prolonged antiplatelet use, the potential risk of delayed rupture, device migration, aneurysm unrelated hemorrhage, delayed parent vessel occlusion, and the worsening of preexisting mass effect ${ }^{11,13,16)}$. Furthermore, treatment of recently ruptured aneurysms with flow diverters is associated with relatively high rebleeding risk, and should be approached cautiously ${ }^{13)}$. Thromboembolisms and perforator infarctions have also been associated with flow diverters. In addition, no randomized trial has been conducted to compare flow diverter with conventional endovascular treatments in terms of safety or efficacy. Recently, a randomized trial called the Flow Diversion for the Treatment of Intracranial Aneurysm Trial, which was designed to study safety and efficacy of flow diverters ${ }^{16)}$, was halted due to safety concerns. It was concluded flow diverters demonstrated no superiority either in terms of safety or efficacy as compared with conventional endovascular treatment, and recommended that more randomized trials are required to determine the role of flow diverters in the treatment of intracranial aneurysms ${ }^{16)}$.

Several conventional endovascular therapeutic options are available, such as parent artery occlusion (PAO) with balloons or coils, selective coil embolization with parent artery preservation, and selective occlusion with Onyx. In general, PAO is considered most effective in cases of unclippable very large or giant intracranial aneurysm ${ }^{22)}$. However, PAO is a limited therapeutic option when BTO fails. In addition, ischemic complications may develop in 5\% to $10 \%$ of patients who have passed $\mathrm{BTO}^{14)}$. Therefore, when practicable, endosaccular coil embolization with parent artery preservation provides a near ideal therapeutic option. In the present study, 24 patients were treated by endosaccular coil embolization with parent artery preservation, and the overall mortality rate was $20.8 \%$. However, the mortality rates of ruptured and unruptured cases were $44.4 \%$ and $6.7 \%$, respectively, and thus, procedurally related morbidity rate and mortality were $12.5 \%$ and $4.2 \%$, respectively, and no rebleeding was encountered during follow-up. In addition, unruptured aneurysm showed more favorable results, which concurs with several reports that demonstrated procedural morbidities of 0-26\%, overall mortalities of 0-29\%, and good clinical outcomes (63-95\%) (Table 4).

The limitations of present study include its retrospective nature, patient selection bias, the recruitment of a limited number of patients, and relatively short follow-up duration. In particular, the angiographic and clinical outcome of the very large of giant aneurysm may differ depending on whether it is ruptured or unruptured, thus the results should have been described in the two groups. However, this study reported the overall outcomes without separating the two groups because the limited number of patients. Nevertheless, our findings suggest the endosaccular treatment of very large and giant intracranial aneurysms might be a feasible and effective therapeutic option. Compensatory interventional and surgical team approaches are also mandatory to treat very large and giant aneurysms.

\section{CONCLUSION}

Although a wide range of endovascular options are available for the treatment of very large and giant intracranial aneurysms, no current technique is completely successful or free from complications. However, the present study suggests endosaccular treatment of very large and giant aneurysm with parent artery preservation provides a feasible, effective treat- 
ment modality with acceptable morbidity and mortality.

\section{CONFLICTS OF INTEREST}

No potential conflict of interest relevant to this article was reported.

\section{INFORMED CONSENT}

Informed consent was obtained from all individual participants included in this study.

\section{References}

1. Becske T, Kallmes DF, Saatci I, McDougall CG, Szikora I, Lanzino G, et al. : Pipeline for uncoilable or failed aneurysms: results from a multicenter clinical trial. Radiology 267 : 858-868, 2013

2. Becske T, Potts MB, Shapiro M, Kallmes DF, Brinjikji W, Saatci I, et al. : Pipeline for uncoilable or failed aneurysms: 3-year follow-up results. J Neurosurg $127: 81-88,2017$

3. Brinjikji W, Murad MH, Lanzino G, Cloft HJ, Kallmes DF : Endovascular treatment of intracranial aneurysms with flow diverters: a meta-analysis. Stroke 44 : 442-447, 2013

4. Chalouhi N, Tjoumakaris S, Gonzalez LF, Dumont AS, Starke RM, Hasan $D$, et al. : Coiling of large and giant aneurysms: complications and longterm results of 334 cases. AJNR Am J Neuroradiol 35 : 546-552, 2014

5. el-Chalouhi N, Jabbour PM, Tjoumakaris SI, Starke RM, Dumont AS, Liu $\mathrm{H}$, et al. : Treatment of large and giant intracranial aneurysms: cost comparison of flow diversion and traditional embolization strategies. World Neurosurg 82 : 696-701, 2014

6. Gao X, Liang G, Li Z, Wei $X$, Cao P : A single-centre experience and follow-up of patients with endovascular coiling of large and giant intracranial aneurysms with parent artery preservation. J Clin Neurosci 19 : 364-369, 2012

7. Gruber A, Killer M, Bavinzski G, Richling B : Clinical and angiographic results of endosaccular coiling treatment of giant and very large intracranial aneurysms: a 7-year, single-center experience. Neurosurgery 45 : 793-803; discussion 803-804, 1999
8. Ha SW, Jang SJ : Clinical analysis of giant intracranial aneurysms with endovascular embolization. J Cerebrovasc Endovasc Neurosurg 14 : 22-28, 2012

9. Hauck EF, Welch BG, White JA, Replogle RE, Purdy PD, Pride LG, et al. : Stent/coil treatment of very large and giant unruptured ophthalmic and cavernous aneurysms. Surg Neurol 71 : 19-24; discussion 24, 2009

10. Jahromi BS, Mocco J, Bang JA, Gologorsky Y, Siddiqui AH, Horowitz MB, et al. : Clinical and angiographic outcome after endovascular management of giant intracranial aneurysms. Neurosurgery 63 : 662-674; discussion 674-675, 2008

11. Kallmes DF, Hanel R, Lopes D, Boccardi E, Bonafe A, Cekirge S, et al. : International retrospective study of the pipeline embolization device: a multicenter aneurysm treatment study. AJNR Am J Neuroradiol 36 : 108-115, 2015

12. Kodama N, Suzuki J : Surgical treatment of giant aneurysms. Neurosurg Rev 5 : 155-160, 1982

13. Leung GK, Tsang AC, Lui WM : Pipeline embolization device for intracranial aneurysm: a systematic review. Clin Neuroradiol 22 : 295-303, 2012

14. Li MH, Li YD, Fang C, Gu BX, Cheng YS, Wang YL, et al. : Endovascular treatment of giant or very large intracranial aneurysms with different modalities: an analysis of 20 cases. Neuroradiology 49 : 819-828, 2007

15. Peerless SJ, Drake CG : Treatment of giant cerebral aneurysms of the anterior circulation. Neurosurg Rev 5 : 149-154, 1982

16. Raymond J, Gentric JC, Darsaut TE, lancu D, Chagnon M, Weill A, et al. : Flow diversion in the treatment of aneurysms: a randomized care trial and registry. J Neurosurg 127 : 454-462, 2017

17. Roy D, Milot G, Raymond J : Endovascular treatment of unruptured aneurysms. Stroke 32 : 1998-2004, 2001

18. Sluzewski M, Menovsky T, van Rooij WJ, Wijnalda D : Coiling of very large or giant cerebral aneurysms: long-term clinical and serial angiographic results. AJNR Am J Neuroradiol 24 : 257-262, 2003

19. Sundt TM, Jr., Piepgras DG : Surgical approach to giant intracranial aneurysms. Operative experience with 80 cases. J Neurosurg 51 : 731742, 1979

20. UCAS Japan Investigators, Morita A, Kirino T, Hashi K, Aoki N, Fukuhara $S$, et al. : The natural course of unruptured cerebral aneurysms in a Japanese cohort. N Engl J Med 366 : 2474-2482, 2012

21. van Rooij WJ, Sluzewski $M$ : Endovascular treatment of large and giant aneurysms. AJNR Am J Neuroradiol 30 : 12-18, 2009

22. van Rooij WJ, Sluzewski M, van der Laak C : Flow diverters for unruptured internal carotid artery aneurysms: dangerous and not yet an alternative for conventional endovascular techniques. AJNR Am J Neuroradiol $34:$ 3-4, 2013 